\title{
The Planar Magneto-Transistor: Topology \& Offset
}

\author{
R. D. Tikhonov ${ }^{1}$ \\ ${ }^{1}$ Scientific-Manufacturing Complex “Technological Centre” MIET, Zelenograd, Moscow, Russia \\ Correspondence: R. D. Tikhonov, Scientific-Manufacturing Complex "Technological Centre" MIET, street 4806, \\ house 5, Zelenograd 124498, Moscow, Russia. E-mail: R.Tikhonov@tcen.ru
}

Received: January 27, 2014

Accepted: February 12, $2014 \quad$ Online Published: February 21, 2014

doi:10.5539/mas.v8n2p56

URL: http://dx.doi.org/10.5539/mas.v8n2p56

\begin{abstract}
We have studied the planar magneto-transistor and experimentally measured the offset to better understand the device. The geometry of the electrodes of a planar magneto-transistor is an essential factor for creating high-performance magneto-transistors. Acquiring an adequate understanding of the device's underlying mechanisms should help to improve its offset.
\end{abstract}

Keywords: planar magneto-transistor, sensitivity, offset

\section{Introduction}

Dual collector magneto-transistors have been studied in great detail (Hudson, 1968; Davies \& Wells, 1971; Vikulin, Glauberman, Vikulina, \& Zaporozhchenko, 1974; Vinal \& Masnari, 1982; Kordic, Zieren, \& Middlehoek, 1983; Baltes \& Popovic, 1986; Cristoloveanu, 1981; Mitnikova, Persiyanov, Rekalova, \& Shtyubner, 1978; Andreou \& Westgate, 1984; Ristic, Smy, \& Baltes, 1988; Nathan, Maenaka, Allegretto, Baltes, \& T Nakamura, 1989; Roumenin, 1994; Riccobene, Gartner, Wachutka, Baltes, \& Fichtner, 1995; Chaplygin, Galushkov, Romanov, \& Volkov, 1995; Kang, Lee, \& Han, 1996; Metz, 1999; Nagy \& Trujillo, 1998; Amelichev, Galushkov, Mirgorodskii, Tikhomirov, Chaplygin, Shorin, \& Shubin, 1999; Vikulin, I., Vikulina, L., \& Stafeev, 2001; Tikhonov, 2005; Oxland, Long, \& Rahman, 2009; Hnatiuc \& Căruntu, 2009; Leepattarapongpan, Phetchakul, Penpondee, Pengpad, Chaowicharat, Hruanun, \& Poyai, 2010; Amelichev, Tikhonov, \& Cheremisinov, 2013; Tikhonov, 2013); however, they are not in use because of a large initial potential imbalance. The analysis (Metz, 1999) of this imbalance was based on the assumption of asymmetric structure. The following was written in conclusion.

"Typical offsets in the MTs chosen as reference are up to a few percent. The offsets vary between individual devices. This variation usually dominates the statistics. A strong local mismatch of the offset between neighboring devices is observed. In addition to this scale variation, variations on a larger scale also contribute to offset. Suppressed sidewall injection magneto-transistors (SSIMT) exibit a quadrupling of the offsets compared to standard MTs. This comes from misalignment of the emitter guard ring. By applying offset reduction approaches, average absolute values as low as $0.11 \%$ are achieved, corresponding to magnetic field equivalent offset of $3.2 \mathrm{mT}$ and $3.9 \mathrm{mT}$ depending on the device. This is lower by a factor of approximately 100 than the worst case equivalent offsets observed in the SSIMTs integrated in the angle detection system". An epigraph is a philosophical phrase H. Weyl "....we had to understand that general organization of nature possesses that [left-right] symmetry. But one will not expect that any special object of nature shows it to perfection."

Tikhonov, Kozlov and Polomoshnov (2008), Tikhonov (2009, 2010a) have demonstrated that transistor current is dependent on the value and sign of the imbalance between collector potentials. This effect is not explained by initial asymmetries. The cause of this initial imbalance remains a mystery in the literature. Mathematical modelling makes it possible to calculate the origin for a given skewness, but this modelling does not predict the potential imbalance. We turn to experimental methods to help determine the origin of this imbalance.

There are no known studies that explore the potential imbalance of planar magneto-transistors. Lateral magneto-transistors are sensitive to magnetic fields directed parallel to the surface of a crystal, while planar magneto-transistors are sensitive to magnetic fields directed to the orthogonal axis of a crystal. These field direction sensitivities are responsible for the different characteristics present in lateral and planar magneto-transistors. This paper presents the results of an experimental study of planar magneto-transistors obtained in a single technological cycle and on the same plates with lateral magneto-transistors. 


\section{The Structure of Planar Magneto-Transistors}

All of the transistors used the same body structure developed for the lateral dual-collector $n-p-n$ bipolar magneto-transistor with a base in the well (Amelichev et al., 2013). The planar transistors used several different topological configurations of electrodes, emitters, collectors and contacts to the base (Figure 1). The designs took into account the current lines of injected carriers in the bipolar magneto-transistor under the action of the Lorentz force (Tikhonov, 2010b; Tikhonov, Kozlov, \& Polomoshnov, 2010).

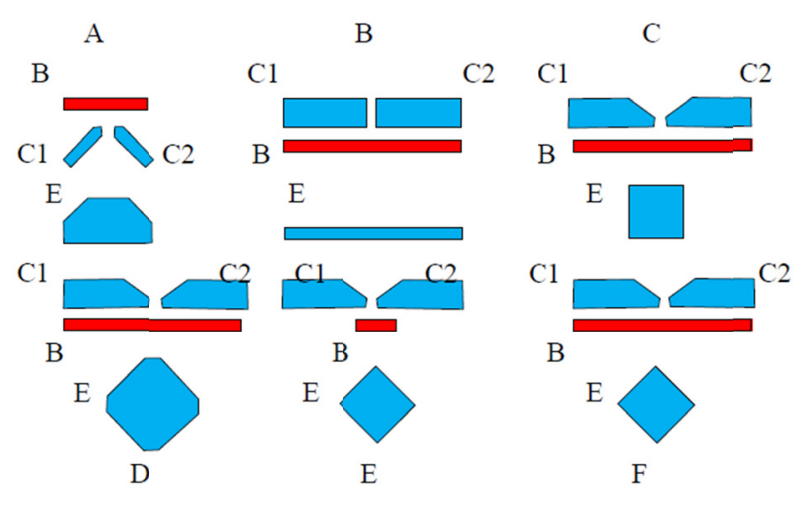

Figure 1. Topology of planar magneto-transistors

Magneto-transistor A had an octagonal emitter with an area of $1000 \mu^{2}$ and eight pairs of collectors. The collectors were arranged with opposite flat sides at an angle of $45^{\circ}$ relative to the emitter. Similar collectors of each pair were joined via metallization. The distance between the emitter and the collectors, $\mathrm{L}_{\mathrm{EC}}$, was $27 \mu$. A square frame next to the base functioned as a heavily doped contact area between the base and the collectors. From this point we will use the following abbreviations: C1-first collector; B-base; E-emitter; C2-second collector.

Magneto-transistor B is a full analogue of the lateral transistor with a $280 \mu$ length of strip electrodes. The distance between the emitter and the collectors was $50 \mu$ and the emitter had an area of $1000 \mu^{2}$. Contacts to the base were located between the emitter and the collectors. Each collector was divided into two parts that were cross-connected via metallization.

Magneto-transistor $\mathrm{C}$ had a square emitter with an area of $1000 \mu^{2}$. The side of the emitter was parallel to the blade edge of the collector and the $\mathrm{L}_{\mathrm{EC}}$ was $27 \mu$. A doped region base formed a single border around the emitter.

Magneto-transistor D had a rhomboid emitter (a square rotated $45^{\circ}$ ) with truncated corners, an area of $2000 \mu^{2}$ and an $\mathrm{L}_{\mathrm{EC}}$ of $22 \mu$.

Magneto-transistor $\mathrm{E}$ had a rhomboid emitter (a square rotated $45^{\circ}$ ) with an area of $1000 \mu^{2}$ and an $\mathrm{L}_{\mathrm{EC}}$ of $27 \mu$. A heavily doped contact area to the base was located opposite the gap between a pair of collectors at the corners of the rhomboid emitter, and this doped area did not form a continuous ring.

Magneto-transistor $\mathrm{F}$ had a rhombic emitter (a square rotated $45^{\circ}$ ) with an area of $1000 \mu^{2}$. Four pairs of collectors were positioned at opposite angles of the emitter so that they formed an angle of $45^{\circ}$ with the emitter. One collector of each pair was connected with the corresponding collectors from the other pairs. A square frame to the base functioned as a heavily doped contact area between the emitter and collectors.

\section{Offset of Planar Magneto-Transistors}

The planar magneto-transistors were measured using the circuit shown in Figure 2, where the resistance in the load collectors $R_{\mathrm{C} 1}$ and $\mathrm{R}_{\mathrm{C} 2}$ was $5,465 \mathrm{k} \Omega$, and the supply voltage, Vdd, was $9 \mathrm{~V}$. Contact $\mathrm{B}$ to the base was not connected with the contact to the well contact W.

The collectors' potential, $U_{\mathrm{C} 1, \mathrm{C} 2}(0)$, initial imbalance of the two collectors' potential, $\mathrm{U}_{\mathrm{C} 1}(0)-\mathrm{U}_{\mathrm{C} 2}(0)$, and the signal in the magnetic field, $\mathrm{U}_{\mathrm{Cl}}(\mathrm{B})-\mathrm{U}_{\mathrm{C} 1}(0)-\mathrm{U}_{\mathrm{C} 2}(\mathrm{~B})+\mathrm{U}_{\mathrm{C} 2}(0)$, were measured at a variable base potential, $\mathrm{U}_{\mathrm{IN}}$. Offset of the magneto-transistor - equivalent magnetic field [31] - is calculated using a formula.

$$
\mathrm{B}_{\text {equiv }}=\left[\mathrm{U}_{\mathrm{C} 1}(0)-\mathrm{U}_{\mathrm{C} 2}(0)\right] \cdot \mathrm{B} /\left[\mathrm{U}_{\mathrm{C} 1}(\mathrm{~B})-\mathrm{U}_{\mathrm{C} 1}(0)-\mathrm{U}_{\mathrm{C} 2}(\mathrm{~B})+\mathrm{U}_{\mathrm{C} 2}(0)\right]
$$

The measurement of the planar transistors was made in a permanent magnetic field, which measured $120 \mathrm{mT}$. When $\mathrm{U}_{\mathrm{C} 1, \mathrm{C} 2}=1.5 \mathrm{~V}$ data are given in Table 1 . 
Table 1. Offset of planar magneto-transistors at $\mathrm{U}_{\mathrm{C} 1, \mathrm{C} 2}=1.5 \mathrm{~V}$

\begin{tabular}{cccc}
\hline Magneto-transistor & $\mathrm{U}_{\mathrm{C} 1}(0)-\mathrm{U}_{\mathrm{C} 2}(0), \mathrm{mV}$ & $\mathrm{U}_{\mathrm{C} 1}(\mathrm{~B})-\mathrm{U}_{\mathrm{Cl}}(0)-\mathrm{U}_{\mathrm{C} 2}(\mathrm{~B})+\mathrm{U}_{\mathrm{C} 2}(0), \mathrm{mV}$ & $\mathrm{B}_{\text {equiv }}, \mathrm{T}$ \\
\hline $\mathrm{A}$ & 695 & 2 & 42 \\
$\mathrm{~B}$ & 133 & 4 & 4 \\
C & 18,4 & 1,52 & 1,45 \\
D & 17,8 & 4 & 0,55 \\
E & 3,8 & 1,3 & 0,35 \\
F & 3,7 & 1,64 & 0,27 \\
\hline
\end{tabular}

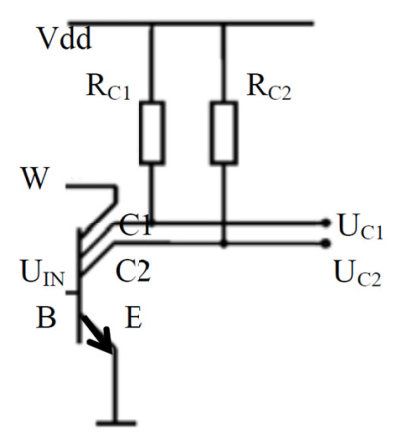

Figure 2. Biasing circuit for the planar magneto-transistor

The offsets of magneto-transistors A - F shown, as a function of the collector potential in Figure 3.

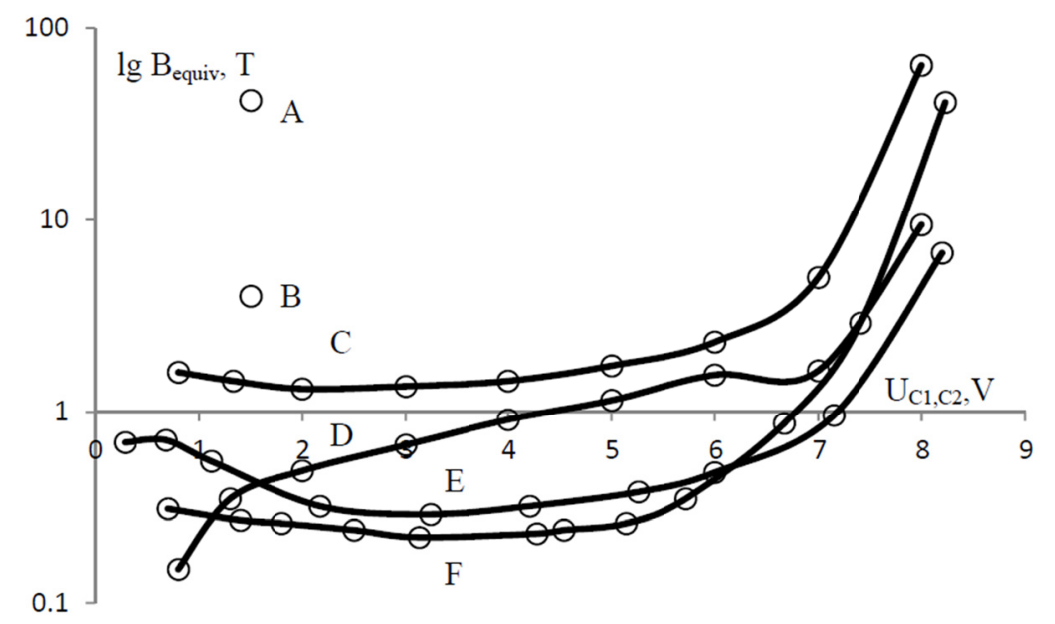

Figure 3. Offset of magneto-transistors, depending on the collector potential

Magneto-transistor A had a high initial imbalance between the two collectors' potential and a small signal in the magnetic field. The electric field was concentrated at the corners of the collectors and the injector. The offset was maximized by the heavily doped square-frame contact area next to the collectors.

Magneto-transistor B had five-times less initial imbalance than the two collector's potential and half more the useful signal in the magnetic field. The equivalent lateral magneto-transistor had a large offset.

Magneto-transistor $\mathrm{C}$ had an initial imbalance that was reduced twenty-five-fold and had half the magnetic field signal. The offset decreased when the emitter was in a square configuration.

Magneto-transistor D had the same offset observed in $\mathrm{C}$ and also had a reduced initial imbalance. The rhomboid emitter with truncated corners produced very interesting results. At low collector's voltage has a small potential imbalance. 
Magneto-transistor $\mathrm{E}$ also had a small offset and the signal in magnetic field was more than twice the signal observed in D. However, this device configuration had more than three-times the initial imbalance of the two collectors' potential. The heavily doped contact area located between the emitter and the collectors did not form a continuous ring and, as a result, there was an increased offset.

Magneto-transistor $\mathrm{F}$ had the smallest offset. The combination of the rhomboid emitter and a heavily doped contact proved to be optimal.

In planar magneto-transistors, the magnetic field is perpendicular to the surface of the crystal. Sensitivity is determined by the variation of the current collector in a plane parallel to the surface of the crystal and by changing the effective length of the base.

\section{Conclusion}

The increase of the initial imbalance of the two collectors' potential is apparently the result of the increased electric field at the corners of the collectors, as spontaneous discharge lightning rod.

The rhombic emitter eliminates competition between the injectors from the angles of the square emitter.

The heavily doped contact area to the base, located between the emitter and the collectors, does not provide leak currents across the surface of the injection. This absence of leak currents is reflected in the reduced imbalance.

The geometry of the magneto-transistors played a vital role; the rhomboidal emitter electrodes, the rectangular collectors and the solid frame of the heavily doped contact contributed to reduce the offset.

It can be concluded that the geometry of the electrodes of a planar magneto-transistor is an essential factor for creating high-performance magneto-transistors. Optimization of the topology will allow magneto-transistors to be used by integrated magnetic sensors.

A small Discovery- figuring the influence of electrode shape on initial voltage imbalance potential collectors of magneto-transistor- can give a broader way to use magneto-transistors.

\section{References}

Amelichev, V. V., Galushkov, A. I., Mirgorodskii, Ju. N., Tikhomirov, P. A., Chaplygin, Ju. A., Shorin, M. V., \& Shubin, S. V. (1999). Dual collectors bipolar magneto-transistor: modeling and termocompensation sensitivity. Sensors and Systems, 6, 38-42.

Amelichev, V. V., Tikhonov, R. D., \& Cheremisinov, A. A. (2013). Microtesla Sensitivity and Noise of a Triple Collector Magneto-transistor. Modern Applied Science, 7(11), 26-32.

Andreou, A. G., \& Westgate, C. R. (1984). The magneto-transistor effect. Electron Lett., 20, 699-701. http://dx.doi.org/10.1049/el:19840480

Baltes, H. P., \& Popovic, R. S. (1986). Integrated Semiconductor Magnetic Field Sensors. Proc. IEEE, 74(8), 1107-1132. http://dx.doi.org/10.1109/PROC.1986.13597

Chaplygin, Y. A., Galushkov, A. I., Romanov, I. M., \& Volkov, S. I. (1995). Experimental research on the sensitivity and noise level of bipolar and CMOS integrated magneto-transistors and judgement of their applicability in weak-field magnetometers. Sensor and Actuators A, Physical, 49(3), 163-166. http://dx.doi.org/10.1016/0924-4247(95)01028-9

Cristoloveanu, S. (1981). Magnetic field and surface influences on double injection phenomena in semiconductors. Phys. Status Solidi(a), 65, 281-292. http://dx.doi.org/10.1002/pssa.2210650133

Davies, L. W., \& Wells, M. S. (1971). Magneto-transistor incorporated in a bipolar IC. Proc. IREE, Aust. 235-238.

Haberli, A., Schneider, M., Malcovati, P., Castagnetti, R., Maloberti, F., \& Baltes, H. (1996, February). 2D magnetic microsensor with on-chip signal processing for contactless angle measurement. In Solid-State Circuits Conference, 1996. Digest of Technical Papers. 42nd ISSCC., 1996 IEEE International (pp. 332-333). IEEE.

Hnatiuc, M., \& Căruntu, G. (2009, January). The optimization of bipolar magneto-transistor structures. In Advanced Topics in Optoelectronics, Microelectronics, and Nanotechnologies IV (pp. 72972M-72972M). International Society for Optics and Photonics. http://dx.doi.org/10.1117/12.823706

Hudson, E. C. (1968). Semiconductive magnetic transducer. US Patent 3389230. 
Kang, U. S., Lee, S. K., \& Han, M. K. (1996). Highly sensitive mangetotransistor with combined phenomena of Hall effect and emitter injection modulation operated in the saturation mode. Sensors and Actuators A: Physical, 54(1), 641-645. http://dx.doi.org/10.1016/S0924-4247(97)80030-1

Kordic, S., Zieren, V., \& Middlehoek, S. (1983). A novel method for reducing the offset of magnetic-field sensors. Sensors and Actuators, 4, 55-61. http://dx.doi.org/10.1016/0250-6874(83)85008-2

Leepattarapongpan, C., Phetchakul, T., Penpondee, N., Pengpad, P., Chaowicharat, E., Hruanun, C., \& Poyai, A. (2010). Magneto-transistor Based on the Carrier Recombination - Deflection Effect. IEEE Sensor Journal, 10(2), 294-299. http://dx.doi.org/10.1109/JSEN.2009.2033812

Metz, M. (1999). Offset in CMOS Magneto-transistors, Analysis and Reduction. Diss.// Zurich, SW, 1-155.

Mitnikova, I. M., Persiyanov, T. V., Rekalova, G. I., \& Shtyubner, G. (1978). Investigation of the characteristics of silicon lateral magneto-transistors with two measuring collectors. Sov. Phys.-Semicond., 12, 26-28.

Nagy, A., \& Trujillo, H. (1998). Highly sensitive magneto-transistor with new topology. Sensors and Actuators A: Physical, 65(2), 97-100. http://dx.doi.org/10.1016/S0924-4247(97)01625-7

Nathan, A., Maenaka, K., Allegretto, W., Baltes, H. P., \& Nakamura, T. (1989). The Hall effect in integrated magneto-transistors. IEEE Trans. Elecron Devices, ED-36, 108-117. http://dx.doi.org/10.1109/16.21189

Oxland, R. K., Long, A. R., \& Rahman, F. (2009). Magnetotransport characterization of surface-treated $\mathrm{InP} / \mathrm{InGaAs}$ heterojunction bipolar transistors. Microelectronic Engineering, 86(12), 2432-2436. http://dx.doi.org/10.1016/j.mee.2009.05.007

Riccobene, C., Gartner, K., Wachutka, G., Baltes, H., \& Fichtner, W. (1995). Full three- dimensional numerical analysis of multi-collector magneto-transistors with directional sensitivity. Sensor and Actuator, A46-47, 289-293. http://dx.doi.org/10.1016/0924-4247(94)00907-Y

Ristic, L., Smy, T., \& Baltes, H. P. (1988). A Lateral Magneto-transistor Structure with a Linear Response to the Magnetic Field. Sensors and Materials, 2, 83-92.

Roumenin, Ch. S. (1994). Solid State Magnetic Sensors. ELSEVIER SCIENCE, Amsterdam-Lausanne-New York-Oxford-Shannon-Tokyo, 1-500.

Tikhonov, R. D. (2005). Sensor on Bipolar Magneto-transistor with Base in Well. Solid State Electronics, 49(8), 1302-1308. http://dx.doi.org/10.1016/j.sse.2005.05.011

Tikhonov, R. D. (2009). An integrated magneto-transistor sensor. Measurement Techniques, 52(4), 410-414. http://dx.doi.org/10.1007/s11018-009-9278-3

Tikhonov, R. D. (2010a). Offset Voltage of an Integrated Magneto-transistor Sensor. Russian Microelectronics, 39(1), 41-53. http://dx.doi.org/10.1134/S1063739710010063

Tikhonov, R. D. (2010b). Lateral and planar bipolar magneto-transistors. Nano- microsystem technika, 6, 31-36.

Tikhonov, R. D. (2013). Triplecollector Magneto-transistor. Lambert Academic Publishing, 1-229.

Tikhonov, R. D., Kozlov, A. V., \& Polomoshnov, S. A. (2008). Imbalance of the potentials of a dual-collector lateral bipolar magneto-transistor. Measurement Techniques, Springer New York, 51(8), 896-902.

Tikhonov, R. D., Kozlov, A. V., \& Polomoshnov, S. A. (2010). The planar magneto-transistor transdusor. Patent $R F, 2422943$.

Vikulin, I. M., Glauberman, M. A., Vikulina, L. F., \& Zaporozhchenko, Y. (1974). Investigation of the characteristics of two-collector magneto-transistor. Sov. Phys.-Semicond., 8, 369-370.

Vikulin, I. M., Vikulina, L. F., \& Stafeev, V. I. (2001). Magneto-sensitive transistors. Review, FTP, 35(1), 3-10.

Vinal, A. W., \& Masnari, N. A. (1982). Magnetic transistor behavior explained by modulation of emitter injection - not carrier deflection. IEEE Electron Device Lett., EDL-3, 203-205. http://dx.doi.org/10.1109/EDL.1982.25551

\section{Copyrights}

Copyright for this article is retained by the author(s), with first publication rights granted to the journal.

This is an open-access article distributed under the terms and conditions of the Creative Commons Attribution license (http://creativecommons.org/licenses/by/3.0/). 